Victoria Transport Policy Institute

1250 Rudlin Street, Victoria, BC, V8V 3R7, CANADA

www.vtpi.org info@vtpi.org

Phone \& Fax 250-360-1560

"Efficiency - Equity - Clarity"

\title{
Efficient Vehicles Versus Efficient Transportation Comparing Transportation Energy Conservation Strategies
}

\author{
By \\ Todd Litman \\ Victoria Transport Policy Institute
}

26 August 2009

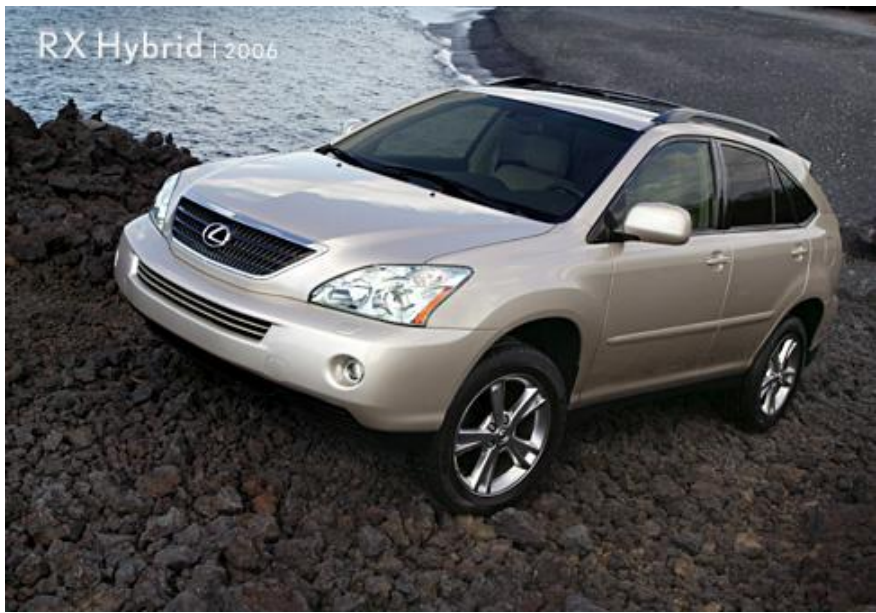

Efficient vehicles, such as this hybrid SUV, consume less fuel per mile but tend to be driven more miles and so increase congestion, road and parking facility costs, crashes and some environmental impacts. This paper investigates these tradeoffs.

\begin{abstract}
This paper compares four transportation energy conservation strategies using a comprehensive evaluation framework that takes into account how each strategy affects annual vehicle travel, and therefore mileage-related impacts such as traffic congestion, road and parking facility costs, and crashes. These mileage-related impacts tend to be large in magnitude compared with energy conservation benefits, so even small changes in total vehicle travel can have a large impact on net benefits. Fuel efficiency standards and some alternative fuels cause vehicle travel to increase. Higher fuel taxes cause a combination of increased vehicle fuel economy and reduced mileage. Mobility management strategies cause relatively large mileage reductions and so provide the greatest mileage-related benefits. Conventional evaluation practices often overlook mileage-related impacts and so tend to overvalue strategies that increase vehicle fuel efficiency and undervalue mobility management strategies.
\end{abstract}

Published in Transport Policy, Volume 12, Issue 2, March 2005, Pages 121-129, (http://authors.elsevier.com/sd/article/S0967070X04000575) 


\section{Introduction}

There are often many possible solutions to a problem. Which is selected often depends on how the problem is evaluated. A particular solution may appear effective and desirable using one evaluation framework, and ineffective and undesirable using another.

Conventional transportation decision-making tends to use a reductionist approach, in which individual organizations evaluate solutions based on narrowly-defined objectives. For example, transport agencies are responsible primarily for reducing traffic congestion and improving mobility, and environmental agencies are responsible for reducing pollution emissions. Each organization evaluates solutions based on their objectives, often giving little consideration to other impacts.

Reductionist decision-making may be appropriate for addressing relatively simple problems, but it tends to fail when dealing with complex, interrelated issues with significant indirect impacts. It can result in organizations implementing solutions to one problem that exacerbate other problems outside their responsibility, and tends to undervalue strategies that provide multiple, diverse benefits.

In recent years economists and planners have developed various techniques for more comprehensive impact analysis, including monetization (measuring in monetary units) of nonmarket impacts such as congestion, crash and environmental costs, and multi-criteria analysis using various scoring and weighting systems (Litman, 2002 and 2004).

This paper uses a comprehensive framework to evaluate four potential transport energy conservation and emission reduction strategies. Each of these strategies can provide comparable energy savings and related emission reductions, but they differ in their impacts on annual vehicle mileage, and therefore their mileage-related costs and benefits. These mileage-related impacts tend to be large in magnitude.

Figure 1 compares the estimated magnitude of various transport costs. The external costs of petroleum consumption (including economic impacts of importing petroleum, environmental impacts of petroleum distribution, and climate change emissions) are typically estimated to be $1-4 \varnothing$ per vehicle-mile $(0.6-2.4 \varnothing$ per $\mathrm{km})$ for an average automobile (NRC, 2001), a relatively small impact compared with other transport costs (monetary values in this paper are in current U.S. dollars). Traffic congestion, road and parking facility costs, crashes and vehicle operating expenses are usually calculated to be larger in magnitude (Murphy and Delucchi, 1998; Dings, Davidson, and Sevenster, 2003; Litman, 2004; European Transport Pricing Initiatives, 2004).

As a result, an energy conservation and emission reduction strategy may not be worthwhile overall if it causes even small increases in other transport costs, while a strategy that reduces other transport costs provides far more total benefits. For example, a strategy that reduces energy consumption and emissions by $10 \%$, but increases traffic congestion, crash and parking costs by $3 \%$ each is probably not worthwhile overall, while a strategy that reduces energy consumption by $10 \%$, and congestion, crash and parking costs by $3 \%$ each provides more than twice the benefits that would be recognized by a reductionist planning process that only considers energy and emission impacts. 
Figure 1 Estimated External Costs Of Automobile Travel (Litman, 2004)

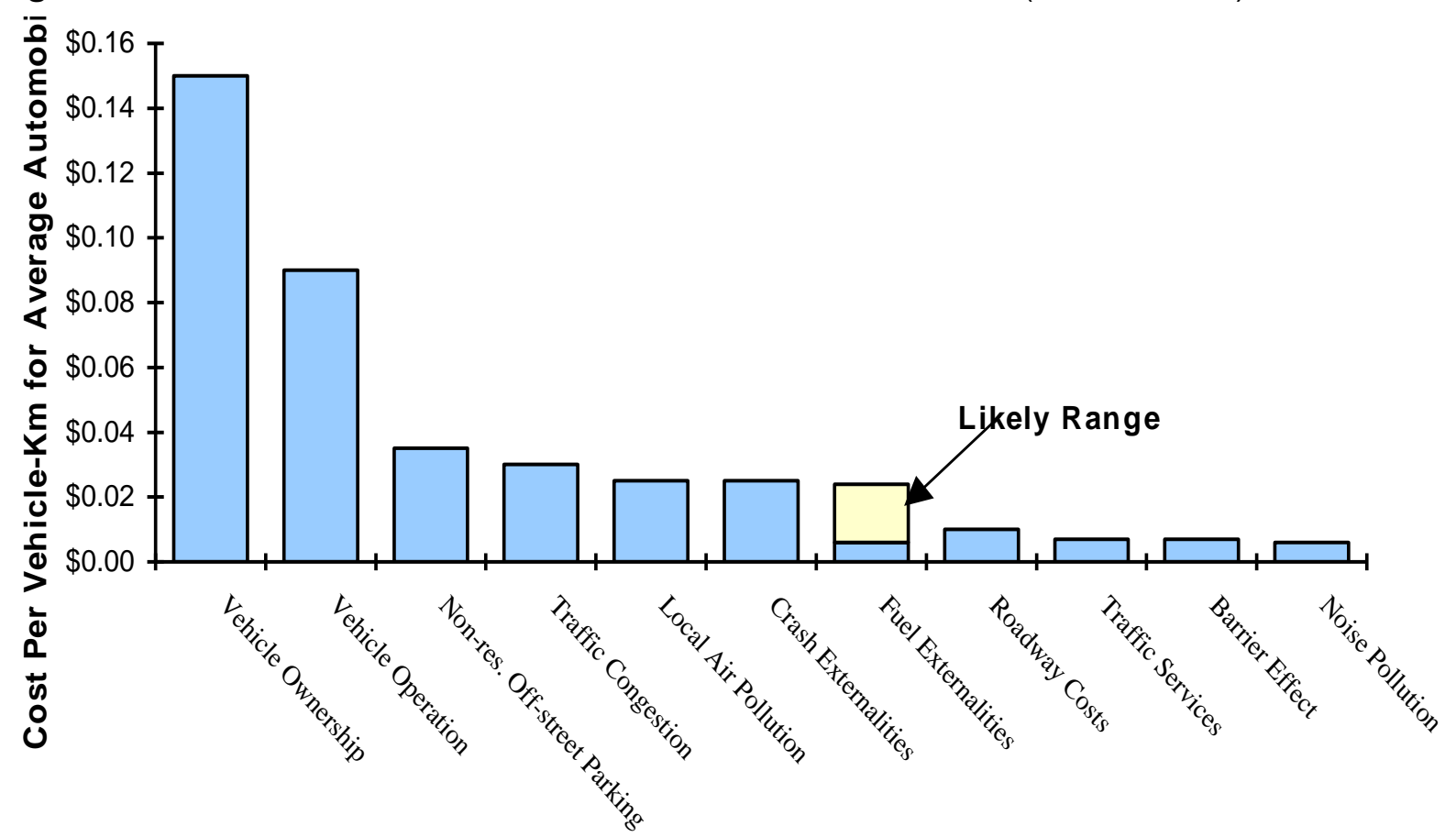

This graph show estimated external costs for an average automobile. Fuel externalities (external costs of producing and distributing petroleum, plus climate change emissions) is a relatively modest cost. (Based on Litman, 2004, converted to kilometers and updated to 2004 U.S. dollars). 


\section{Evaluation Framework}

This analysis uses an evaluation framework with the nine planning objectives described in Table 1. Individual strategies are rated by the author according to the degree they support each objective, using a seven-point scale, from 3 (most beneficial) to -3 (most harmful). Ratings in this paper are based on the authors' judgment (the "Notes" columns in tables 2-5 provide brief explanations of these ratings). This framework is reasonably comprehensive but not too complex. Of course, it could be expanded by adding more objectives (such as physical fitness), by disaggregating categories (for example, by having separate categories for different pollutants), by weighting the objectives, and by using a panel of experts and stakeholders to rate impacts, but such elaborations are not necessary for this level of analysis, which is primarily illustrative.

Except for equity and affordability, these objectives are directly related to vehicle travel. All else being equal, a change in annual vehicle mileage causes a similar change in energy consumption, pollution emissions, congestion, road and parking facility costs, crashes, sprawl and mobility benefits, although the relationships are not exactly proportional. ${ }^{1}$

\section{Table $1 \quad$ Planning Objectives}

\begin{tabular}{|l|l|}
\hline \multicolumn{1}{|c|}{ Objective } & \multicolumn{1}{|c|}{ Description } \\
\hline Energy Conservation & Reductions in per capita transport energy consumption and $\mathrm{CO}_{2}$ emissions. \\
\hline Emission Reductions & $\begin{array}{l}\text { Reductions in "conventional" pollution emissions, including NOx, VOCs, CO, } \\
\text { particulates, toxics, water pollution and noise. }\end{array}$ \\
\hline Congestion Reduction & Reduced traffic congestion. \\
\hline Road and Parking Savings & Reduced road and parking facility costs. \\
\hline Traffic Safety & Reduced per capita crash damages, injuries and fatalities. \\
\hline $\begin{array}{l}\text { Strategic Land Use } \\
\text { Objectives }\end{array}$ & $\begin{array}{l}\text { Reductions in per capita impervious surface, more accessible development patterns, } \\
\text { more livable communities. }\end{array}$ \\
\hline Equity Objectives & $\begin{array}{l}\text { Improved accessibility for people who are transportation-disadvantaged, and fairer } \\
\text { distribution of benefits and costs. }\end{array}$ \\
\hline Affordability & Vehicle cost savings and more affordable transport options. \\
\hline Mobility Benefits & Benefits to consumers from increased mobility. \\
\hline
\end{tabular}

This table describes the planning objectives used in this evaluation framework.

An important factor in this analysis is the effect prices have on vehicle travel and fuel consumption, defined as the elasticity of annual vehicle mileage with respect to per-mile vehicle operating costs, and the elasticity of fuel consumption with respect to fuel price. Numerous studies have examined these relationships ("Transportation Elasticities," VTPI 2004; TRL 2004). They indicate that the elasticity of vehicle travel with respect to fuel price is typically -0.15 in the short run and -0.3 over the long run, which means that a

\footnotetext{
${ }^{1}$ For example, parking costs decline with a reduction in vehicle trips but not with a reduction in trip length. Congestion declines if urban-peak mileage is reduced, but much less if off-peak or rural mileage is reduced. Certain types of mileage reductions provide greater crash reductions or user benefits than others.
} 
$10 \%$ fuel price increase reduces driving about $1.5 \%$ within one year and $3 \%$ after several years (Oum, Waters, and Yong 1992; Glaister and Graham 2000).

Fuel consumption changes more than vehicle mileage because fuel prices affect vehicle fuel economy as well as vehicle travel. ${ }^{2}$ For example, Agras and Chapman (1999) find long-run elasticity of vehicle travel with respect to fuel price is -0.32 , and the elasticity of fuel economy with respect to fuel price is 0.60 , which sum to an overall long-run fuel price elasticity of -0.92 . This means that a $10 \%$ fuel price increase will over the long-run reduce driving by $3.2 \%$ and improve fuel economy by $6.0 \%$, leading to a $9 \%$ overall reduction in fuel consumption.

Conversely, purchase of more fuel efficient vehicles leads to increased annual mileage, because it reduces the per-mile cost of driving. Estimates of the elasticity of annual vehicle mileage with respect to per-mile costs range from about -0.3 to nearly -1.0 . Walter McManus, an auto industry researcher at the University of Michigan's Transportation Research Institute in Ann Arbor, is quoted in a Christian Scientist Monitor article as saying that, for every 1 percent decline in the cost of fuel, Americans drive 1.85 percent more miles (Clayton 2005).

More recent analysis suggests that U.S. vehicle travel may have become less price sensitive in the short-run, apparently due to more automobile-dependent land use development that reduces travel options (Hughes, Knittel and Sperling 2007).

\footnotetext{
2 "Fuel economy" refers to fuel consumption rates per mile or kilometer. "Fuel efficiency" refers to the mechanical efficiency of the vehicle. Consumers may use increased fuel efficiency to purchase larger, higher-performance vehicles without improving fuel economy.
} 


\section{Energy Conservation and Emission Reduction Strategies}

This section describes four energy and emission reduction strategies, discusses their impacts on vehicle mileage, and evaluates them with respect to planning objectives.

\section{Fuel Efficiency Standards and Feebates}

Fuel efficiency standards require manufactures to sell more fuel efficient vehicles (NRC 2001; CBO 2003). Feebates provide a rebate on the purchase of fuel-efficient vehicles funded by a surcharge on the purchase of fuel-inefficient vehicles (NRT 1998). These are widely promoted energy conservation strategies (ACEEE 2005).

Mileage Impacts: Increasing vehicle fuel-efficiency reduces per-mile operating costs, causing annual vehicle mileage to increase, as described earlier in the discussion of price elasticities. This is called a rebound or takeback effect (Alexander 1997; Greene 1998; UKERC 2007). This effect is typically estimated at $20-40 \%$, so a $10 \%$ fuel economy gain increases vehicle mileage $2-4 \%$, resulting in $6-8 \%$ net fuel savings. ${ }^{3}$ This effect tends to increase with energy prices. For example, the difference in per-mile operating costs between a 20 and 30 mile-per-gallon vehicle increases as fuel prices increase from $\$ 1.50$ to $\$ 2.50$ per gallon, causing greater mileage reductions. Some studies indicate that rebound effects are declining due to rising incomes and declining real fuel prices (Small and Van Dender 2007), but many analysts expect real fuel prices to increase in the future (Campbell and Laherrere, 1998; Wikipedia), which is likely to increase rebound effectives. This study assumes the long-run rebound effect is $33 \%$, so increasing average vehicle fuel economy $15 \%$ causes average annual mileage to increase $5 \%$, resulting in a $10 \%$ net savings.

Other Impacts: Increased vehicle travel increases mileage-related costs such as traffic congestion, facility costs, crashes and sprawl. Higher fuel economy may reduce per-mile emission rates of some pollutants, such as VOCs, but not others, such as NOx and particulates (fuel economy often involves a trade-off with these emissions), and increased mileage increases emissions per vehicle-year. Increased fuel economy tends to reduce operating costs but increases vehicle production costs. The increased vehicle mileage increases mobility benefits but reduces consumer vehicle purchase options.

Table 2 Fuel Efficiency Standards and Feebates - Impact Summary

\begin{tabular}{|l|c|l|}
\hline \multicolumn{1}{|c|}{ Objective } & Rating & \multicolumn{1}{c|}{ Notes } \\
\hline Energy Conservation & +3 & Can achieve 10\% energy savings. \\
\hline Emission Reductions & +1 & Reduces some emissions (VOCs) but not others. \\
\hline Congestion Reduction & -3 & Increased peak-period travel increases congestion costs. \\
\hline Road and Parking Savings & -2 & Increased vehicle travel increases road and parking facility costs. \\
\hline Traffic Safety & -3 & $\begin{array}{l}\text { Increased vehicle travel increases crashes, vehicle weight } \\
\text { reductions may increase crash severity. }\end{array}$ \\
\hline Strategic Land Use Objectives & -2 & Reduced operating costs encourages land use dispersion. \\
\hline Equity Objectives & 0 & No clear equity impacts. \\
\hline Affordability & 0 & Mixed impacts: higher production and lower operating costs. \\
\hline Mobility Benefits & +2 & Increased vehicle travel provides consumer benefits. \\
\hline
\end{tabular}

Rating from 3 (very beneficial) to -3 (very harmful). A 0 indicates no impact or mixed impacts.

\footnotetext{
${ }^{3}$ Some researchers find smaller rebound values, in the 5-15\% range, but their analysis generally reflect short- and medium-run time periods and so represent lower-bound values.
} 


\section{Alternative Fuels}

Various incentives and regulations can be used to encourage the production, sale and use of alternative fuel vehicles, including diesel, LPG, methanol, ethanol, hydrogen and electricity. These fuels reduce per-mile energy consumption and emissions, although net benefits are sometimes small when all impacts are evaluated on a lifecycle basis (Kreith, Norton and Potestio, 1995; McCubbin and Delucchi, 1997).

Mileage Impacts: Vehicle mileage impacts vary. Some alternative fuels reduce per-mile vehicle operating costs (often due to favorable tax treatment and production subsidies) and so increase vehicle travel. For this analysis we assume that an alternative fuel that reduces climate change emissions by $10 \%$ will increase average annual vehicle travel by $3 \%$.

Other Impacts: Alternative fuel vehicles have mixed impacts on safety, reducing some risks and increasing others (Bricker, 1997). For example, electric vehicles reduce risks associated with petroleum fires, and increase risks associated with battery chemicals, electrical shocks, and crash risk to pedestrians and cyclists (because electric vehicles are quiet at lower speeds). Impacts on conventional air pollutants vary. For example, diesel fuel increases particulates and sulfur emissions, and methanol and ethanol increase some toxic emissions. Electric vehicles eliminate tailpipe emissions but their overall emission impacts depend on the marginal electrical generation fuel. Consumer impacts are mixed: most alternative fuel vehicles have higher purchase costs and lower operating costs, and some reduce vehicle performance (speed, range and carrying capacity).

\section{Table $3 \quad$ Alternative Fuels - Impact Summary}

\begin{tabular}{|l|c|l|}
\hline \multicolumn{1}{|c|}{ Objective } & Rating & \multicolumn{1}{c|}{ Notes } \\
\hline Energy Conservation & +3 & Can achieve 10\% climate change emission reductions. \\
\hline Emission Reductions & +1 & Most alternative fuels reduce some pollution emissions. \\
\hline Congestion Reduction & -1 & Increased peak-period travel increases congestion costs. \\
\hline Road and Parking Savings & -1 & Increased vehicle travel increases road and parking facility costs. \\
\hline Traffic Safety & -1 & Increased vehicle mileage increases crashes. \\
\hline Strategic Land Use Objectives & -1 & Lower operating costs encourages more dispersed land use. \\
\hline Equity Objectives & 0 & No clear equity impacts. \\
\hline Affordability & 0 & Usually mixed: higher production and lower operating costs. \\
\hline Mobility Benefits & +1 & Increased vehicle travel provides consumer benefits. \\
\hline
\end{tabular}

Rating from 3 (very beneficial) to -3 (very harmful). A 0 indicates no impact or mixed impacts. 


\section{Fuel Tax Increase}

Fuel tax increases give consumers a direct incentive to conserve energy. Fuel tax increases can be justified on a number of grounds in addition to energy conservation (particularly in low fuel tax countries such as the U.S. and Canada), as a way to charge for road use, to internalize fuel production externalities, and as a tax shifting strategy (Metschies, 2001; “Fuel Price Increases," VTPI, 2004; CBO, 2003).

Mileage Impacts: As described earlier, higher fuel prices cause a combination of reduced driving and increased fuel economy. This analysis assumes that the fuel tax increase required to reduce energy consumption by $10 \%$ would reduce vehicle travel by $3.5 \%$, reflecting common vehicle travel elasticity values.

Other Impacts: By reducing annual vehicle travel, fuel tax increases reduce mileage-related costs such as traffic congestion, road and parking facility costs, crashes and sprawl. This strategy tends to result in smaller vehicles that increase crash injuries to occupants but reduce damages to other road users $(\mathrm{CBO}, 2003)$. It has mixed equity impacts: although it reduces vehicle travel affordability (reduced vertical equity), it internalizes a greater portion of motor vehicle costs (increased horizontal equity) and increases transport options for nondrivers (increased vertical equity). Overall impacts on affordability and consumer welfare depends on the quality of vehicle and transport options available, and how revenues are used (if consumers can easily purchase more fuel efficient vehicles, easily shift to other modes, or benefit from reductions in other taxes, they can be better off overall).

Table $4 \quad$ Fuel Tax Increase - Impact Summary

\begin{tabular}{|l|c|l|}
\hline \multicolumn{1}{|c|}{ Objective } & Rating & \multicolumn{1}{c|}{ Notes } \\
\hline Energy Conservation & +3 & Can achieve 10\% climate change emission reductions. \\
\hline Emission Reductions & +2 & $\begin{array}{l}3.5 \% \text { mileage reduction reduces emissions 3.5\%. Increased vehicle } \\
\text { efficiency provides modest additional emission reductions. }\end{array}$ \\
\hline Congestion Reduction & +1 & Reduced peak-period travel and congestion. \\
\hline Road and Parking Savings & +1 & Reduced vehicle travel reduces facility costs. \\
\hline Traffic Safety & 0 & $\begin{array}{l}\text { Reduced vehicle mileage reduces crashes, but lighter vehicles may } \\
\text { increase crash severity in some cases. }\end{array}$ \\
\hline Strategic Land Use Objectives & +2 & Increased vehicle operating costs encourages more clustered land use. \\
\hline Equity Objectives & +1 & Increases horizontal equity (road cost recovery). May be regressive. \\
\hline Affordability & -1 & $\begin{array}{l}\text { Overall impacts on consumer affordability depend on the quality of } \\
\text { options available and how revenues are used. }\end{array}$ \\
\hline Mobility Benefits & -1 & Reduces vehicle travel which reduces consumer benefits. \\
\hline
\end{tabular}

Rating from 3 (very beneficial) to -3 (very harmful). A 0 indicates no impact or mixed impacts. 


\section{Mobility Management}

Mobility management includes various strategies that encourage more efficient travel patterns (VTPI, 2004; European Program for Mobility Management, 2004; Konsult, 2004). These include various road and parking pricing reforms, improvements to alternative modes, commute trip reduction and community-based marketing programs that encourage travel changes, and land use management reforms.

This analysis evaluates Pay-As-You-Drive (PAYD) vehicle insurance (Litman, 1997; CentsPerMileNow, 2004; Environmental Defense, 2004), although other mobility management strategies could have similar impacts. PAYD means that a vehicle's insurance premiums are prorated by annual mileage. Existing rating factors are incorporated so higher-risk motorists pay more per mile than lower-risk drivers. For example, a $\$ 375$ annual premium becomes $3 \phi$ per mile, and a $\$ 2,000$ premium becomes $16 \phi$ per mile. A typical U.S. motorists would pay about $7 \phi$ per mile. This is equivalent to a $60 \%$ increase in fuel prices, but is not a new fee at all, simply a different way of paying an existing fee. By converting a currently fixed cost into a mileage-based variable cost motorists have a new opportunity to save money. Motorists who continue driving current average mileage pay the same as they do now (excepting any additional administrative costs), but those who reduce mileage save money. Travel reductions in response to this incentive represent net consumer surplus gains: low-value vehicle-miles motorists willingly give up in exchange for financial savings.

Mileage Impacts: Mobility management uses vehicle travel reductions to reduce fuel use, so vehicle travel reductions are proportional to energy savings. Pay-As-You-Drive insurance is predicted to reduce participating vehicle's average annual travel by $10 \%$ (this reflects lower-bound price elasticity values applied to a $7 \varnothing$ per vehicle-mile fee).

Other Impacts: Mobility management reduces mileage-related transport costs such as congestion, road and parking facility costs and crashes. PAYD insurance supports equity and affordability objectives. Since it uses positive incentives (motorists who continue their current mileage are no worse off than they are now, but they have a new opportunity to save money if they drive less), vehicle travel reductions reflects net consumer benefits.

\section{Table $5 \quad$ Mobility Management - Impact Summary}

\begin{tabular}{|l|c|l|}
\hline \multicolumn{1}{|c|}{ Objective } & Rating & \multicolumn{1}{c|}{ Notes } \\
\hline Energy Conservation & +3 & Can achieve 10\% climate change emission reductions. \\
\hline Emission Reductions & +3 & $10 \%$ mileage reduction reduces all emissions 10\%. \\
\hline Congestion Reduction & +2 & Reduced peak-period travel reduces congestion. \\
\hline Road and Parking Savings & +2 & Reduced vehicle travel reduces road and parking facility use. \\
\hline Traffic Safety & +3 & $\begin{array}{l}\text { Reduced vehicle travel reduces crashes. Higher-risk drivers have the } \\
\text { greatest incentive to reduce mileage, providing additional benefits. }\end{array}$ \\
\hline Strategic Land Use Objectives & +2 & Encourages more clustered land use. \\
\hline Equity Objectives & +2 & $\begin{array}{l}\text { Increases horizontal equity (increased actuarial accuracy) and tends } \\
\text { to be progressive with respect to income. }\end{array}$ \\
\hline Affordability & +2 & Increases insurance affordability. \\
\hline Mobility Benefits & 0 & $\begin{array}{l}\text { Reduces vehicle travel which reduces consumer benefits. Mileage } \\
\text { reductions consists of marginal-value vehicle travel motorists } \\
\text { willingly forego in exchange for financial savings. }\end{array}$ \\
\hline
\end{tabular}

Rating from 3 (very beneficial) to -3 (very harmful). A 0 indicates no impact or mixed impacts. 


\section{Qualitative Impacts Summary}

Table 6 summarizes the results of this qualitative analysis, showing how each energy conservation strategy rates according to the nine planning objectives.

Table 6 Qualitative Analysis Summary

\begin{tabular}{|c|c|c|c|c|}
\hline Objective & $\begin{array}{c}\text { Fuel Efficiency } \\
\text { Standards }\end{array}$ & $\begin{array}{c}\text { Alternative } \\
\text { Fuels }\end{array}$ & $\begin{array}{c}\text { Fuel Tax } \\
\text { Increases }\end{array}$ & $\begin{array}{c}\text { Mobility } \\
\text { Management }\end{array}$ \\
\hline Energy Conservation & +3 & +3 & +3 & +3 \\
\hline Emission Reductions & +1 & +1 & +2 & +3 \\
\hline Congestion Reduction & -3 & -1 & +1 & +2 \\
\hline Road and Parking Savings & -2 & -1 & +1 & +2 \\
\hline Traffic Safety & -3 & -1 & 0 & +3 \\
\hline Strategic Land Use Objectives & -2 & -1 & +2 & +2 \\
\hline Equity Objectives & 0 & 0 & +1 & +2 \\
\hline Affordability & 0 & 0 & -1 & +2 \\
\hline Mobility Benefits & +2 & +1 & -1 & 0 \\
\hline Totals & -4 & +1 & +8 & +19 \\
\hline
\end{tabular}

This table compares how each strategy rates with respect to the nine objectives, using ratings from +3 (very beneficial) to -3 (very harmful). All strategies provide the same energy conservation benefits, but have different impacts with regard to other planning objectives.

All four strategies are assumed to reduce energy consumption the same amount, but fuel efficiency standards and feebates receive low ratings in most other categories because they increase vehicle travel which increases mileage-related costs. The increased vehicle travel provides mobility benefits, although these tend to be small, since the additional travel consists of marginal value trips. These strategies provide little consumer financial savings since fuel cost savings are largely offset by increased vehicle production costs.

Alternative fuel impacts vary. Vehicles powered by solar-powered electric reduce total air emissions, $\mathrm{CNG}$ and conventionally-produced electricity provide moderate emission reductions, while diesel or alcohol fuels can increase total pollution costs. To the degree that alternative fuels reduce vehicle operating costs they increase vehicle travel, providing mobility benefits and increasing mileage-related costs.

Fuel tax increases cause moderate reductions in vehicle travel, providing moderate reductions in mileage-related costs. This strategy increases direct consumer costs but these are economic transfers which can be offset by other tax reductions. It causes small reductions in mobility benefits, the cost of which depends on how easily consumers can increase vehicle fuel efficiency or reduce their vehicle travel.

Mobility management provides the greatest vehicle travel reductions, and so provides the greatest reduction in mileage-related costs. Most strategies also help achieve equity and affordability objectives. They reduce mobility benefits, but the loss is small because the travel foregone consists of marginal value vehicle-miles. Consumer impacts depend on the quality of transport alternatives available. Since PAYD insurance uses positive incentives (motorists who continue driving their current mileage are no worse off than they are now, but they have a new opportunity to save money if they drive less), any reduction in vehicle travel reflects net consumer benefits. 


\section{Quantitative Analysis}

Various studies provide monetized estimates of various transport impacts, such as those in Figure 1 (Murphy and Delucchi, 1998; Dings, Davidson, and Sevenster, 2003; Litman, 2004; European Transport Pricing Initiatives, 2004; Wright and Fulton, 2005). Monetized values are better than qualitative ratings for this type of analysis because they are easily understood and implicitly weigh the relative magnitude of impacts, for example, allowing the relative importance of congestion, crash and pollution impacts to be compared. Cost values from Litman (2004) were converted from miles to kilometers, updated to 2004 U.S. dollars using the U.S. Consumer Price Index, and adjusted when appropriate to reflect the specific type of travel impacts caused by these strategies.

Vehicle fuel consumption is estimated to have external costs that average $1.8 \phi$ per vehicle-kilometer for an average automobile (based on a range from $0.6 \varnothing$ to $2.4 \varnothing$ per kilometer, or $3 \phi$ to $10 \phi$ per liter of gasoline in external costs beyond current taxes, as indicated in NRC, 2001 and studies citied in Litman, 2004).

A relatively low value is used for parking costs, since mileage reductions are likely to consist of a combination of reduced vehicle trips, which provide parking cost savings, and reduced vehicle trip length, which do not. Although total parking costs average more than $7 \varnothing$ per vehicle-kilometer, a value of $3.5 \phi$ per kilometer is used in this analysis, reflecting an assumption that about half of mileage reductions result from reduced vehicle trips.

Traffic congestion costs are estimated to average $3 \phi$ per vehicle-kilometer overall (higher under urban-peak conditions, and lower under other conditions). Local air pollution emissions are estimated to average $2.5 \varnothing$ per vehicle-kilometer. Although fuel efficiency standards and alternative fuels increase mileage, this is not considered to increase local air pollution emissions per vehicle-year due to reductions in per-mile emission rates, as discussed earlier. Roadway costs not funded through fuel taxes are estimated to average $1 \varnothing$ per vehicle-mile. Traffic services, such as policing and emergency services average $0.7 \not$ per vehicle-kilometer. The Barrier Effect (also 0.7 $\varnothing$ per vehicle-kilometer) refers to delays vehicle traffic causes to non-motorized modes. Traffic noise is estimated to average $0.6 \notin$ per vehicle-kilometer.

Consumer surplus impacts of transport price changes are calculated using the "rule of half" (Small, 1999). This takes into account financial gains or losses and changes in mobility benefits (i.e., the incremental benefits to consumers of increased vehicle travel, and the increased costs resulting from mileage reductions). If a $4 \varnothing$ per vehicle-kilometer price increase (reduction) causes a reduction (increase) in vehicle travel, the net change in consumers surplus is estimated to average $2 \varnothing$ per additional (reduced) vehicle-kilometer. In the case of Pay-As-You-Drive insurance, if an additional $4 \phi$ per vehicle-kilometer financial savings results in an average reduction of 2,000 annual vehicle-kilometers, the net gain in consumer surplus is $\$ 40$ (\$80 financial savings minus $\$ 40$ in reduced mobility benefits). 
Table $7 \quad$ Quantitative Analysis - Changes in Net Benefits Per Vehicle-Year

\begin{tabular}{|l|r|r|r|r|r|}
\hline & \multicolumn{1}{|c|}{$\begin{array}{c}\text { Cost } \\
\text { Values }\end{array}$} & $\begin{array}{c}\text { Fuel Efficiency } \\
\text { Standards }\end{array}$ & $\begin{array}{c}\text { Alternative } \\
\text { Fuels }\end{array}$ & \multicolumn{1}{c|}{$\begin{array}{c}\text { Fuel } \\
\text { Taxes }\end{array}$} & $\begin{array}{c}\text { Mobility } \\
\text { Management }\end{array}$ \\
\cline { 1 - 4 } \multicolumn{2}{|c|}{ Annual Mileage Change } & $5 \%(+1,000 \mathrm{~km})$ & $3 \%(+600 \mathrm{~km})$ & $-3.5 \%(-700 \mathrm{~km})$ & $-10 \%(-2,000 \mathrm{~km})$. \\
\hline Energy Conservation & $\$ 0.018$ & $\$ 36.00$ & $\$ 36.00$ & $\$ 36.00$ & $\$ 36.00$ \\
\hline Parking Externalities & $-\$ 0.035$ & $-\$ 35.00$ & $-\$ 21.00$ & $\$ 24.50$ & $\$ 70.00$ \\
\hline Traffic Congestion & $-\$ 0.030$ & $-\$ 30.00$ & $-\$ 18.00$ & $\$ 21.00$ & $\$ 60.00$ \\
\hline Local Air Pollution & $-\$ 0.025$ & $\$ 0.00$ & $\$ 0.00$ & $\$ 17.50$ & $\$ 50.00$ \\
\hline Crash Externalities & $-\$ 0.025$ & $-\$ 25.00$ & $-\$ 15.00$ & $\$ 17.50$ & $\$ 50.00$ \\
\hline Roadway Costs & $-\$ 0.010$ & $-\$ 10.00$ & $-\$ 6.00$ & $\$ 7.00$ & $\$ 20.00$ \\
\hline Traffic Services & $-\$ 0.007$ & $-\$ 7.00$ & $-\$ 4.20$ & $\$ 4.90$ & $\$ 14.00$ \\
\hline Barrier Effect & $-\$ 0.007$ & $-\$ 7.00$ & $-\$ 4.20$ & $\$ 4.90$ & $\$ 14.00$ \\
\hline Noise Pollution & $-\$ 0.006$ & $-\$ 6.00$ & $-\$ 3.60$ & $\$ 4.20$ & $\$ 12.00$ \\
\hline Consumer Surplus & $\$ 0.020$ & $\$ 20.00$ & $\$ 12.00$ & $-\$ 14.00$ & $\$ 40.00$ \\
\hline \multicolumn{1}{|r|}{ Totals } & $-\$ 0.107$ & $-\$ 64.00$ & $-\$ 24.00$ & $\$ 123.50$ & $\$ 366.00$ \\
\hline
\end{tabular}

This table summarizes economic impacts. A positive value indicates reduced costs or increased benefits, a negative value indicates higher costs or reduced benefits. The second row shows changes in annual vehicle travel relative to a 20,000 $\mathrm{km}$ base. The second column indicates the per-km cost values used in this analysis, based on Litman, 2004. All four strategies provide the same energy conservation benefits, but they differ in mileage-related impacts.

Table 7 summarizes the results of this quantitative evaluation of the four energy conservation strategies. The second row indicates the changes in average annual vehicle travel. The second column indicates the cost values used for analysis. All four strategies reduce fuel consumption $10 \%$, but they differ in other impacts, primarily due to their differing effects on vehicle travel. Figure 2 illustrates these impacts. Values above the zero line indicate benefits, values below that line indicate costs.

\section{Figure 2 Quantitative Analysis - Changes in Annual Costs}

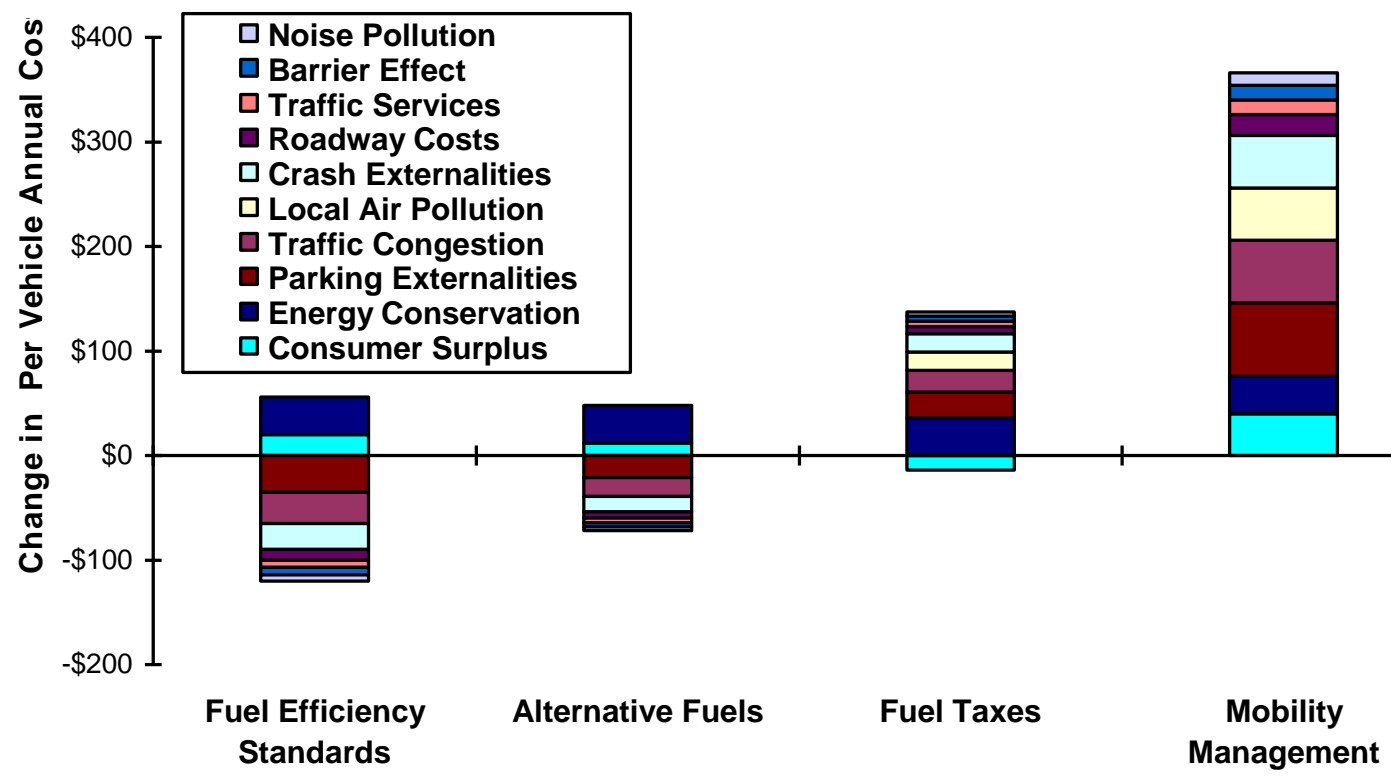

This graph illustrates how the four energy conservation strategies affect costs and benefits. Above the zero line indicates benefits, below the line indicates costs. 
Fuel Efficiency Standards that increase average vehicle fuel efficiency by $15 \%$ are estimated to increase annual vehicle travel by $5 \%$ (from 20,000 to 21,000 average annual $\mathrm{kms}$ ), resulting in a $10 \%$ net energy savings and a $5 \%$ increase in mileage-related costs such as congestion, facility costs and crashes. In this case the energy conservation, emission reduction and mobility benefits are more than offset by increased mileagerelated costs.

Alternative fuels can reduce vehicle operating costs, depending on the type of fuel and its tax rate. This analysis assumes that alternative fuel vehicles are cheaper to drive so travel increases $3 \%$, and any additional emissions from the increased mileage is offset by net reductions in per-kilometer emission rates, although actual impacts vary depending on the type of alternative fuel used.

A $15 \%$ vehicle fuel price increase would reduce long-run fuel consumption an estimated $10 \%$, a third of which consists of reduced vehicle travel. This $3.5 \%$ reduction in vehicle $\mathrm{kms}$ provides modest reductions in mileage-related costs, resulting in net social benefits, even taking into account the loss of consumer surplus from reduced vehicle travel.

Mobility management, such as Pay-As-You-Drive vehicle insurance, provides the greatest reduction in vehicle travel, and so provides the greatest reduction in mileagerelated costs. It also causes the greatest reduction in mobility benefits, but because these reduction result from voluntary responses to a new opportunity to save money (consumers would only choose this option if they consider themselves better off overall), they reflect net consumer benefits. Overall, this option provides the greatest net benefits (Parry, 2005).

Of course, the results of this analysis reflect various assumptions and estimates, and some impacts, such as land use and equity impacts, are omitted altogether because they are difficult to monetize. However, the results are consistent with the qualitative analysis and are logical: since many transport costs increase with vehicle travel, energy conservation strategies that increase mileage will increase these costs, reducing net benefits, while energy conservation strategies that reduce vehicle mileage reduce these costs, increasing net benefits.

This analysis uses standard transport economic evaluation methods to account for the consumer surplus impacts of changes in mobility, that is, the changes in direct benefits to consumers from changes in their annual mileage. The results indicate that the value of this impact tends to be small, since marginal changes in annual vehicle mileage consist of consumers' least valued vehicle travel, that is, the vehicle-miles they are most willing to forego in response to modest financial incentives. If mileage is reduced in response to a voluntary financial incentive, consumers must be better off overall or they would not accept the offer. As a result, pricing reforms such as Pay-As-You-Drive insurance provide net consumer surplus benefits. 


\section{Current Evaluation Practices}

How things are measured and evaluated can affect their perceived value. A particular activity or option may seem desirable and successful when evaluated one way, but undesirable and ineffective when measured in another (Litman, 2003). It is therefore important to understand the assumptions and implications of different types of measurements (Litman, 2005).

Planning concerned only with reducing energy consumption and related vehicle emissions often concludes that the best strategy is to encourage or require the purchase of more efficient and cleaner vehicles. Hybrid cars are now commercially available that use a third as much fuel and produce much less emissions per vehicle-mile as the fleet average. But driving such vehicles does not reduce congestion, road and parking facility costs, most consumer costs, accident costs, mobility problems facing non-drivers, or the environmental impacts of roads and sprawl; in fact, by reducing vehicle operating costs, it tends to increase these problems.

Current transport evaluation practices generally overlook impacts that result from changes in vehicle mileage. For example, there is considerable debate concerning the safety impacts of fuel efficiency standards and fuel taxes (NRC, 2002). Critics argue that these strategies force consumers to purchase vehicles that are less safe per mile driven, but there little discussion of additional crashes resulting from increased vehicle travel. If rebound effects are considered at all, the analysis is usually limited to how much it erodes energy conservation benefits. Little attention is given to the traffic congestion, road and parking facility cost, crash, and land use impacts resulting from changes in mileage. When such impacts are recognized at all, they are seldom quantified.

A recent U.S. Congressional Budget Office study evaluating fuel economy standards and higher fuel taxes does mention that CAFE standards would increase total vehicle mileage, and therefore congestion and crash costs, while fuel tax increases would provide congestion and crash reduction benefits, but makes no attempt to quantify these impacts (CBO, 2003).

Similarly, a study sponsored by the Canadian government to evaluate potential transport climate change emission reduction strategies incorporated some co-benefits, but this was limited to reductions in local air pollution emissions (TC, 1999). The analysis did not consider changes in mileage-related costs (congestion, roadway facility costs, crashes and sprawl) and so undervalued mobility management strategies (Litman, 2001). 


\section{Conclusions}

It is important to use a comprehensive framework when evaluating transportation policy and planning options. A limited analysis can result in solutions to one problem that exacerbate other problems, resulting in little or no benefit overall. Efforts to increase vehicle fuel economy or reduce congestion can reduce overall transport system efficiency by exacerbating market distortions and leading to economically excessive vehicle travel. Mobility increases but total benefits to society decline.

This paper evaluates four transport energy conservation strategies using a framework that considers seven planning objectives, and accounts for the consumer surplus impacts from changes in vehicle mileage. It uses both qualitative (based on the author's ratings) and quantitative (based on published monetized cost estimates) analysis. The analysis could be improved by using a panel of experts and stakeholders to rate impacts and select cost values, and perhaps by weighting impacts and adding sensitivity analysis. However, the basic conclusions are unlikely to change significantly with more sophisticated analysis. According to standard monetized values widely used by transport economists, mileagerelated impacts such as congestion, facility costs and accidents are generally larger in magnitude than energy conservation benefits, so ignoring them can result in the selection of energy conservation strategies that provide negative net benefits to society. In particular, strategies that increase vehicle mileage provide less total benefit, while strategies that reduce mileage provide greater total benefit, than recognized by conventional analysis that ignores mileage-related impacts.

Each of the four strategies evaluated provides the same energy savings, but their other impacts vary significantly. Fuel economy standards and some alternative fuels reduce the cost of driving and so increase annual vehicle travel and associated costs. Fuel tax increases and mobility management strategies reduce vehicle travel, providing additional benefits.

Since these strategies affect marginal value vehicle travel (the vehicle-miles consumers are most willing to forego), consumer surplus impacts are small. The additional mileage resulting from more fuel efficient vehicles provides only modest direct consumer benefits, while the reduction in vehicle mileage from higher fuel taxes and other transport pricing reforms cause relatively small loss of consumer benefits, and these can be offset if revenues are returned to consumers as reductions in other costs or improved services. Put differently, energy conservation and emission reduction strategies reduce transport system efficiency if they exacerbate existing market distortions (such as underpricing), and increase system efficiency to the degree that they reflect market principles ("Market Principles," VTPI, 2004).

Some planners may consider comprehensive analysis excessively difficult to apply. But comprehensive analysis is an opportunity to identify opportunities for cooperation among divergent interests, and so can gain support for energy conservation strategies by groups that have little interest in this objective. People and organizations concerned with congestion, road and parking facility costs, safety, economic development, consumer costs, community livability, and equity issues all have reasons to support strategies that reduce economically-excessive vehicle travel ("Win-Win Solutions," VTPI, 2004). 


\section{References}

ACEEE (2005), Vehicle Fuel Economy Standards: Big Energy Savings at a Modest Cost, American Council for and Energy Efficient Economy (www.aceee.org/energy/cafe.htm).

Agras, J. and Chapman, D. (1999), "The Kyoto Protocol, CAFE Standards, and Gasoline Taxes," Contemporary Economic Policy, Vol. 17, No. 3, in, (2001) Policy Notes: A Brief Reference on

Fuel Costs and Fuel Efficiency, Vol. 5 No. 1.

(www.odot.state.or.us/tdb/policy/Policy Notes/jan2001.pdf).

M. Alexander (1997), The Rebound Effect in Energy Conservation, PhD Dissertation (www.leprechaun.com/econ.html).

Alternative Fuels Data Center (www.afdc.doe.gov), US Department of Energy.

S. Bernow and W. Dougherty (2000), "The Impacts of the Kyoto Protocol on Full Cost Transportation in the U.S.," Social Costs and Sustainable Mobility, ZEW, Physica-Verlag (Heidelberg), pp. 56-69.

A. Bricker, et al. (1997), Environmental Impacts and Safety of Electric Vehicles, International Center for Technology Assessment, Washington DC.

BTS (2001), National Transportation Statistics, Bureau of Transportation Statistics (www.bts.gov).

Cambridge Systematics (2009), Moving Cooler: Transportation Strategies to Reduce Greenhouse Gas Emissions (www.movingcooler.info), co-sponsored by a variety of organizations; report at http://commerce.uli.org/misc/movingcooler.pdf; summary at http://commerce.uli.org/misc/movingcoolerexecsum.pdf.

C. Campbell and J. Laherrere (1998), "The End of Cheap Oil," Scientific American, March 1998, pp. $78-83$.

CBO (2003), Fuel Economy Standards Versus A Gasoline Tax, Congressional Budget Office (www.cbo.gov); at www.cbo.gov/ftpdocs/49xx/doc4917/12-24-03_CAFE.pdf.

CentsPerMileNow (2004), (www.centspermilenow.org).

Mark Clayton (2005), "Hybrid-Happy?," Christian Science Monitor (www.csmonitor.com), May 19, 2005; available at www.alternet.org/envirohealth/22051.

Mark Delucchi (1996), Emissions of Criteria Pollutants, Toxic Air Pollutants, and Greenhouse Gases, from the Use of Alternative Transport Modes and Fuels, UC Transportation Center (www.its.ucdavis.edu), No. 344.

Jos M.W. Dings, Marc D. Davidson and Maartje N. Sevenster (2003), External And Infrastructure Costs Of Road And Rail Transport - Analysing European Studies, CE (www.ce.nl) for the Dutch Ministry of Transport, Water Management and Public Works.

Patrick Arthur Driscoll, Ásdís Hlökk Theodórsdóttir, Tim Richardson and Patience Mguni (2012), "Is the Future of Mobility Electric? Learning from Contested Storylines of Sustainable 
Mobility in Iceland," European Planning Studies, Vol. 20, No. 4, pp. 627-639, DOI: 10.1080/09654313.2012.665036.

Environmental Defense PAYD Website (2004), (www.actionnetwork.org/campaign/payd).

European Program for Mobility Management (2004), (www.epommweb.org).

European Transport Pricing Initiatives (2004), (www.transport-pricing.net) includes various efforts to develop more fair and efficient pricing, including ExternE (http://externe.jrc.es) TRACE (www.hcg.nl/projects/trace/trace1.htm) and $\underline{\text { UNITE }}$ (www.its.leeds.ac.uk/projects/unite).

S Glaister, and D. Graham (2000), The Effect of Fuel Prices on Motorists, AA Motoring Policy Unit (www.theaa.com) and the UK Petroleum Industry Association (http://195.167.162.28/policyviews/pdf/effect_fuel_prices.pdf), Sept. 2000.

David Greene (1998), “Why CAFE Worked.” Energy Policy, Vol. 26, No. 8, pp. 595-613.

Jonathan E Hughes, Christopher R. Knittel and Daniel Sperling (2007), Short-Run Gasoline Demand Elasticity: Evidence of Structural Change in the U.S. Market for Gasoline, Paper 071934, Transportation Research Board Annual Meeting (www.trb.org); at www.econ.ucdavis.edu/faculty/knittel/papers/gas demand 083006.pdf.

A. N. Kleit (2002), Impacts of Long-range Increases in the Corporate Average Fuel Economy (CAFE) Standard, Working Paper 02-10, AEI-Brookings Joint Center for Regulatory Studies (www.aei.brookings.org).

Konsult: Knowledgebase on Sustainable Urban Land Use and Transport (2004) (www.elsevier.com/gej-ng/29/29/konsult).

F. Kreith, P. Norton and D. Potestio (1995), "Electric Vehicles: Promise and Reality," Transportation Quarterly, Vol. 49, No. 2, Spring, pp. 5-21.

Todd Litman (1997), "Distance-Based Vehicle Insurance as a TDM Strategy," Transportation Quarterly, Vol. 51, No. 3, Summer 1997, pp. 119-138. A revised version of this paper is available at the Victoria Transport Policy Institute website (www.vtpi.org).

Todd Litman (2001), How Canadian Climate Change Emission Reduction Analysis Undervalues $T D M$, Victoria Transport Policy Institute (www.vtpi.org).

Todd Litman (2002), What's It Worth? Life Cycle and Benefit/Cost Analysis for Evaluating Economic Value, Presented at Internet Symposium on Benefit-Cost Analysis, Transportation Association of Canada (www.tac-atc.ca), 2001; available at VTPI (www.vtpi.org).

Todd Litman (2003), "Measuring Transportation: Traffic, Mobility and Accessibility," ITE Journal (www.ite.org), Vol. 73, No. 10, October 2003, pp. 28-32, available at Victoria Transport Policy Institute website (www.vtpi.org).

Todd Litman (2004), Transportation Cost and Benefit Analysis; Techniques, Estimates and Implications, Victoria Transport Policy Institute (www.vtip.org/tca).

Todd Litman (2005), Well Measured: Developing Indicators for Comprehensive and Sustainable Transport Planning, Victoria Transport Policy Institute (www.vtip.org/tca). 
Todd Litman (2007), Transportation Elasticities, VTPI (www.vtpi.org); at www.vtpi.org/elasticities.pdf.

Todd Litman (2008), Smart Transportation Emission Reduction Strategies, Victoria Transport Policy Institute (www.vtpi.org); at www.vtpi.org/ster.pdf.

Todd Litman (2013), "Comprehensive Evaluation Of Energy Conservation And Emission Reduction Policies," Transportation Research A, Vol. 47, January, pp. 153-166 (http://dx.doi.org/10.1016/j.tra.2012.10.022); at www.vtpi.org/comp em eval.pdf.

Nicholas Lutsey and Daniel Sperling (2005), "Energy Efficiency, Fuel Economy, and Policy Implications," Transportation Research Record 1941, TRB (www.trb.org), pp. 8-17.

McCubbin, Donald and Delucchi, Mark (1997), Social Cost of the Health Effects of MotorVehicle Air Pollution, UC Davis, ITS (www.its.ucdavis.edu).

Metschies, G. (2001), Fuel Prices and Taxation, with Comparative Tables for 160 Countries, German Agency for Technical Cooperation (www.zietlow.com/docs/Fuel\%202000.pdf).

J. Murphy and M. Delucchi (1998), "A Review of the Literature on the Social Cost of Motor Vehicle Use in the United States," Journal of Transportation And Statistics, Vol. 1, No. 1, Bureau of Transportation Statistics (www.bts.gov), January 1998, pp. 15-42.

D. Norland and K. Ninassi (1998), Price It Right; Energy Pricing and Fundamental Tax Reform, Alliance to Save Energy, Washington DC (www.ase.org).

NRC (2001), Effectiveness and Impact of Corporate Average Fuel Efficiency (CAFE) Standards, National Academy Press (www.nap.edu/html/cafe).

NRT (1998), Greenhouse Gas Emissions from Urban Transportation, National Round Table on Environment and Economy (www.nrtee-trnee.ca/publications/Colour/URBTRANE.pdf).

T.H. Oum, W.G. Waters and J. Yong (1992), "Concepts of Price Elasticities of Transport Demand and Recent Empirical Estimates, Journal of Transport Economics, May 1992, pp. 139154.

Ian W.H. Parry (2005), Is Pay-As-You-Drive Insurance: a Better Way to Reduce Gasoline than Gasoline Taxes?, Resources for the Future (www.rff.org/Documents/RFF-DP-05-15.pdf).

Kenneth Small (1999), "Project Evaluation," in Transportation Policy and Economics, Brookings (www.brookings.edu), 1999; also available at UCTC (www.uctc.net/papers/379.pdf).

Kenneth A. Small and Kurt Van Dender (2007), "Fuel Efficiency and Motor Vehicle Travel: The Declining Rebound Effect," Energy Journal, Vol. 28, No. 1, pp. 25-51; at www.econ.uci.edu/docs/2005-06/Small-03.pdf. Also see "If Cars Were More Efficient, Would We Use Less Fuel?," Access, Number 31, University of California Transportation Center (www.uctc.net/access), Fall 2007, pp. 8-13.

TC (1999), Transportation and Climate Change: Options for Action, Transport Canada (www.tc.gc.ca/envaffairs/english/climatechange/ttable). 
TRB (2003), Effectiveness and Impact of Corporate Average Fuel Economy (CAFE) Standard,. Transportation Research Board (www.trb.org).

TRL (2004), The Demand for Public Transit: A Practical Guide, Transportation Research Laboratory, Report TRL 593 (www.trl.co.uk); available at www.demandforpublictransport.co.uk.

UKERC (2007), The Rebound Effect: An Assessment Of The Evidence For Economy-Wide Energy Savings From Improved Energy Efficiency, The Technology And Policy Assessment Function Of The UK Energy Research Centre (www.ukerc.ac.uk); at www.ukerc.ac.uk/support/tiki-index.php?page=ReboundEffect.

VTPI (1998), Win-Win Transportation Management Strategies, VTPI (www.vtpi.org).

VTPI (2004), Online TDM Encyclopedia, Victoria Transport Policy Institute (www.vtpi.org).

Wikipedia (2005), "Hubbert Peak,” Wikipedia, (www.answers.com/topic/hubbert-peak).

Lloyd Wright and Lewis Fulton (2005), "Climate Change Mitigation and Transport in Developing Nations," Transport Reviews (www.tandf.co.uk), Vol. 25, No. 6, November 2005, pp. 691-717.

www.vtpi.org/cafe.pdf 